\title{
Individualised PPI prescription in patients on combination antiplatelet therapy and upper gastrointestinal events after percutaneous coronary intervention: a cohort study
}

\author{
Rahel Häuptle ${ }^{1,2}$, Daniel Weilenmann ${ }^{3}$, Tino Schneider ${ }^{4}$, Sarah R. Haile ${ }^{5,6}$, Peter Ammann ${ }^{3}$, Christina Knellwolf ${ }^{7}$ \\ and Jan Borovicka ${ }^{7}$ \\ ${ }^{1}$ University of Zurich, Zurich, Switzerland \\ ${ }^{2}$ Department of Internal Medicine, Spital Herisau, Appenzell Ausserrhoden, Herisau, Switzerland \\ ${ }^{3}$ Department of Internal Medicine, Cardiology, Kantonsspital St. Gallen, St. Gallen, Switzerland \\ ${ }^{4}$ Department of Internal Medicine, Pneumology, Kantonsspital Graubünden, Chur, Switzerland \\ ${ }^{5}$ Division of Biostatistics, Institute for Social and Preventive Medicine, University of Zurich, \\ Zurich, Switzerland \\ ${ }^{6}$ Clinical Trials Unit, Kantonsspital St. Gallen, St. Gallen, Switzerland \\ ${ }^{7}$ Department of Internal Medicine, Gastroenterology and Hepatology, Kantonsspital St. Gallen, \\ St. Gallen, Switzerland
}

Received July 8, 2011, accepted (after revision) January 2, 2012

\section{Individualisierte Protonenpumpeninhibitor (PPI)-Gabe bei Patienten mit kombinierter Thrombozytenaggregationshemmung} (Aspirin und Clopidogrel) und unerwünschten gastrointestinalen Ereignissen nach perkutaner koronarer Intervention (PCl): Eine Kohortenstudie

Zusammenfassung. Grundlagen: In einer Patientenkohorte, welche nach perkutaner koronarer Intervention (PCI) kombinierte Thrombozytenaggregationshemmung (Aspirin und Clopidogrel) erhielt, wurde die Wirksamkeit einer individualisierten PPI-Gabe zur Reduktion unerwünschter gastrointestinaler Ereignisse untersucht.

Methodik: Das gastrointestinale Risikofaktorprofil und andere Parameter wurden aus einer speziell angelegten elektronischen Datenbank extrahiert. Die Patienten wurden via standardisierten Fragebogen kontaktiert und bei Patienten mit unerwünschten gastrointestinalen Ereignissen wurde zusätzlich ein strukturiertes Telefoninterview durchgeführt.

Ergebnisse: In einer Kohorte von 718 Patienten erhielten 87 $(12,1 \%)$ eine prophylaktische PPI-Therapie. Bei insgesamt $12 \%$ wurden unerwünschte gastrointestinale Ereignisse gefunden, wobei $18,4 \%$ eine PPI-Prophylaxe und $11,1 \%$ kein PPI hatten (OR 1,80, $P=0,054)$. Eine Komedikation mit Steroiden war der

Correspondence: Rahel Häuptle, M.D., Department of Internal Medicine, Spital Herisau, Appenzell Ausserrhoden, Spitalstrasse 6, 9100 Herisau, Switzerland.

Fax: ++41-071 35321 20, E-mail: rahel.haeuptle@yahoo.de hauptsächliche Risikofaktor für unerwünschte gastrointestinale Ereignissen (adjusted OR 5,45, $P=0,014$ ).

Schlussfolgerungen: Die individualisierte PPI-Therapie basierend auf einer Risikoabschätzung für gastrointestinale Blutungsereignisse scheint ein effizientes Instrument $\mathrm{zu}$ sein, um gastrointestinale Ereignisse nach PCI zu minimieren.

Schlüsselwörter: Kombinierte Thrombozytenaggregationshemmung, proton pump inhibitor-Prophylaxe, gastrointestinale Nebenwirkung, gastrointestinaler Risikofaktor

Summary. Background: We investigated the effect of individualised proton pump inhibitors (PPI) prescription on upper gastrointestinal adverse events in a cohort of patients who received combination antiplatelet therapy (aspirin and clopidogrel) after percutaneous coronary intervention (PCI).

Methods: Upper gastrointestinal risk factors and other parameters were extracted from a dedicated electronic database. Patients were contacted with a standardised questionnaire. A structured phone interview was performed in all patients with upper gastrointestinal adverse events.

Results: A cohort of 718 patients on combination therapy yielded $87(12.1 \%)$ patients with prophylactic PPI treatment. Upper gastrointestinal adverse events occurred in $18.4 \%$ patients with and in $11.1 \%$ patients without prophylactic PPI (OR 1.80, $P=0.054)$. Co-treatment with corticosteroids was the main identifiable risk factor for upper gastrointestinal adverse events (adjusted OR 5.45, $P=0.014$ ).

Conclusions: Individualised prescription of PPI-prophylaxis after PCI in patients on combined antiplatelet therapy based on 
risk assessment for upper gastrointestinal bleeding seems to represent an effective measure to minimise upper gastrointestinal adverse events after PCI.

Key words: Combination antiplatelet therapy, prophylactic proton pump inhibitor, upper gastrointestinal adverse event, gastrointestinal risk factor

\section{Introduction}

Combination antiplatelet therapy has become a standard therapy in the treatment of acute coronary syndrome (ACS) and is following percutaneous coronary intervention (PCI) [1].

Two major studies investigated the clinical outcome in patients receiving aspirin and clopidogrel after PCI (CURE study) [2] and after ischemic stroke/TIA (MATCH study) [3] as compared to monotherapy. Although the CURE study showed a better clinical outcome in the combination therapy arm, both studies had significantly higher bleeding rates (including of gastrointestinal (GI) origin) in patients receiving the combination treatment of aspirin and clopidogrel [2, 3]. Gastrointestinal bleeding events occurred in $8.5 \%$ (CURE study) and in 7.6\% (MATCH study) of patients receiving combination antiplatelet therapy, respectively [4].

The following risk factors increased upper GI adverse events (UGI-AE) considerably: History of a previous gastrointestinal event, age $\geq 65$ years, anticoagulation, corticosteroids and high-dose NSAID or multiple NSAID or NSAID plus low-dose aspirin [5]. To decrease the incidence of UGI-AE in patients at risk, proton pump inhibitors (PPI) have been shown to be beneficial and are indicated as co-treatment of aspirin or NSAIDs [6-9].

Although previous studies have shown a benefit of PPI prophylaxis in patients at specific UGI-bleeding risk profiles and on monotherapy with low-dose aspirin or clopidogrel, respectively, the indication for a PPI prescription remained at physician's discretion [8-14]. Recently, after a US expert consensus report from 2008, patients with combination antiplatelet therapy have qualified to receive a PPI prophylaxis no matter what UGI-bleeding risk they are at [9]. However, besides immersive costs produced by this new guideline, there are studies reporting an interaction between clopidogrel and some PPIs reducing the cardioprotective effect of clopidogrel $[14,15]$. Though recent investigations could not confirm this thesis, the effect of PPIs on clopidogrel-based cardioprotection remains to be clarified [16, 17].

Accordingly, there is a controversy going on about how far patients on combination antiplatelet therapy profit from a general PPI prophylaxis. There are little data that patients in a real-life setting would experience significantly more UGI-AE when PPIs were prescribed in an individualised rather than a generalised manner according to UGI-bleeding risk factors. We therefore conducted a retrospective cohort study at a single centre in patients on combination antiplatelet therapy when PPI-prescription was still at physician's discretion. We wanted to investigate the effect of PPI prescriptions on the UGI-AE rate in patients on combination antiplatelet therapy after PCI and to analyse if a general PPI prophylaxis may have been beneficial in patients at low risk for UGI-AE.

\section{Methods}

The study protocol was approved by the ethics committee of the Kanton St. Gallen.

\section{Database and inclusion criteria}

During the period from January 1, 2005 to December 31, 2006, 1500 PCI patients were assessed. All patient records were retrieved from our hospital database, in which patients with coronary angiography and PCI are registered. Due to current recommendations patients with non-ST segment elevation myocardial infarction (NSTEMI) and ST segment elevation myocardial infarction (STEMI) received a combination antiplatelet therapy with aspirin and clopidogrel for twelve months after PCI.

In addition, the following parameters were collected and analysed: prescription of aspirin, clopidogrel, PPI (Omeprazole, Esomeprazole, Pantoprazole, Lansoprazole and Rabeprazole), dicumarine and corticosteroid use. Medical reports of upper and lower GI endoscopy within one year after PCI were reviewed. Endoscopy reports were analysed for indications and endoscopic lesions (UGI bleeding, ulcers, erosions, lower GI bleeding).

All patients were hospitalised due to acute coronary syndrome for PCI. During hospitalisation a complete history of gastrointestinal symptoms was taken. The decision making on PPI prescription as a prophylaxis for gastroduodenal ulcer history after PCI was based on history of upper GI bleeding, chronic NSAID-use and GERD. The decision was made by the treating cardiologist or internal specialist.

\section{Exclusion criteria}

Patients who declined giving informed consent, patients with pre-existing GI symptoms not relating to peptic ulcer disease (e.g. pancreatic cancer and other malignant diseases) and patients who could not be 
reached for additional interviews in the further analysis process, were excluded.

\section{Questionnaire}

A symptoms-based questionnaire about the 12 months period after PCI was sent to 1500 patients. The questionnaire was piloted and adapted in 10 volunteers not involved in medical issues. Patients were asked to answer the following questions:

1. Duration of antiplatelet treatment:

a) Did you take Aspirin ${ }^{\circledR}$ and Plavix ${ }^{\circledR}$ (clopidogrel) for 1 year after PCI?

b) Did you take either Aspirin ${ }^{\circledR}$ or Plavix ${ }^{\circledR}$ for 1 year after PCI?

c) Did you take none of them for 1 year after PCI?

2. Did you suffer from any new symptoms in the first year after PCI? If yes, what did you suffer from?
a) Dyspepsia (nausea, stomach pain)
b) Throwing up blood
c) Black stool
d) Anal bleeding
e) Anything else, namely ... ?

3. What was your reaction to your new symptoms?
a) I did not report my symptoms and they disappeared.

b) I consulted my family doctor.

c) I went to the hospital.

4. Space for any comment.

\section{Structured telephone interview}

To get more precise information, a structured telephone interview was performed in all 137 patients, who reported either an UGI-AE in the questionnaire or had a documentation of endoscopic lesions possibly caused by aspirin/clopidogrel. The aim of this interview was to clarify misleading symptoms and to stratify the risk profile of patients with an UGI-AE.

The telephone interview in form of a prompt sheet contained questions about medication with aspirin, clopidogrel, dicumarine, PPI, corticosteroids, NSAID, previous ulcer, previous endoscopies and H. pyloriinfection. Symptoms were inquired in detail, especially their relation to combination antiplatelet therapy.

\section{Degree of adverse events (AE)}

Concerning concomitance and avoiding over-counting, we analysed UGI-AEs only once per person according to priority: For UGI-AEs the most severe degree were ulcers and erosions including UGI bleeding, followed by hematemesis, overt bleeding with black stools and dyspepsia.

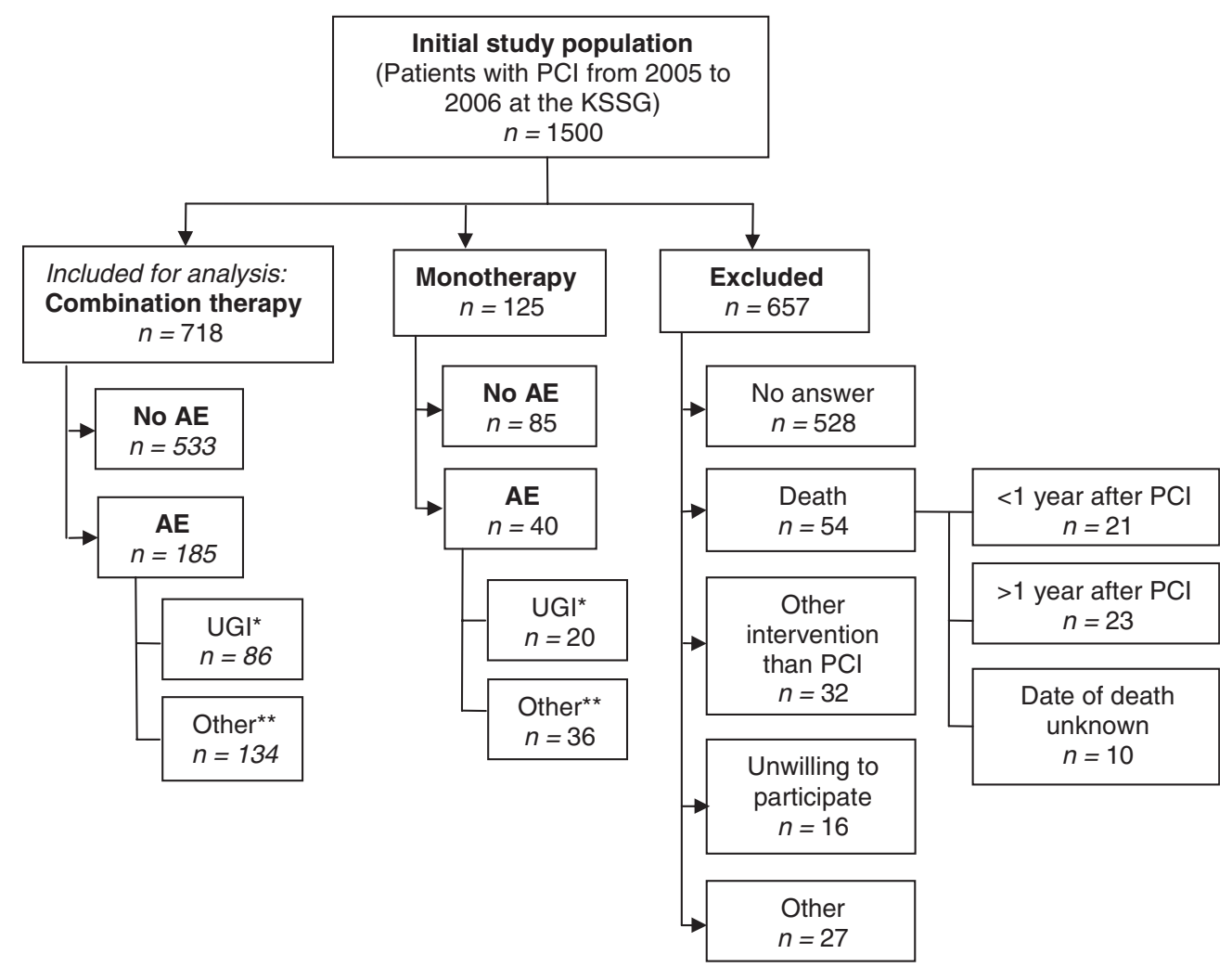

Fig. 1: Selection of study population. *UGI=ulcer, erosion, upper Gl bleeding, overt bleeding and dyspepsia. ** Other =lower GI bleeding, anal bleeding, bleeding of other organs, skin and ENT bleeding, dizziness/cardiovascular dysregulation, hypersensitivity, headache, musculoskeletal and not otherwise specified AEs 


\section{original article}

Primary and secondary endpoint

Primary endpoints were severe adverse events (SAE) of UGI-AE. SAE were defined as a prolongation of hospi- talisation, rehospitalisation in relation to an UGI-AE or endoscopically proven UGI bleeding. Secondary endpoints were the occurrence of any UGI-AE as there were

Tab. 1: Characteristics of the study cohort with combination antiplatelet therapy after PCI

\section{Prophylactic PPI (\%) No prophylactic PPI (\%) $\quad P$-value $n=87$ $n=631$}

\begin{tabular}{|c|c|c|c|}
\hline \multicolumn{4}{|l|}{$n$} \\
\hline Age, mean (SD) yr & $68(9)$ & $64(11)$ & $<0.001$ \\
\hline Sex & & & ns \\
\hline Male & $61(70.1)$ & $469(74.3)$ & \\
\hline Female & $26(29.9)$ & $162(25.7)$ & \\
\hline UGI-AE & $16(18.4)$ & $70(11.1)$ & ns \\
\hline Upper GI bleeding (E) & $0(0)$ & $2(0.3)$ & ns \\
\hline Ulcer (E) & $0(0)$ & $2(0.3)$ & ns \\
\hline Erosion (E) & $2(0.3)$ & $2(0.3)$ & ns \\
\hline Black stool & $4(4.6)$ & $15(2.4)$ & ns \\
\hline Hematemesis & $0(0)$ & $2(0.3)$ & ns \\
\hline Dyspepsia & $11(12.6)$ & $60(9.5)$ & ns \\
\hline Bleeding-AE other than UGI-AE & $12(13.8)$ & $92(14.6)$ & ns \\
\hline Lower GI bleeding (E) & $1(1.1)$ & $6(1)$ & ns \\
\hline Anal bleeding & $5(5.7)$ & $17(2.7)$ & ns \\
\hline Bleeding of other organs & $0(0)$ & $5(0.8)$ & ns \\
\hline Skin bleeding & $6(6.9)$ & $54(8.6)$ & ns \\
\hline ENT* bleeding & $1(1.1)$ & $19(3)$ & ns \\
\hline Other AE & $6(6.9)$ & $30(4.8)$ & ns \\
\hline Dizziness/cardiovascular dysregulation & $0(0)$ & $9(1.4)$ & ns \\
\hline Hypersensitivity & $4(4.6)$ & $8(1.3)$ & 0.023 \\
\hline Headache & $2(2.3)$ & $3(0.5)$ & ns \\
\hline Musculoskeletal & $0(0)$ & $5(0.8)$ & ns \\
\hline Others & $0(0)$ & $7(1.1)$ & ns \\
\hline \multicolumn{4}{|l|}{ UGI-bleeding risk factors } \\
\hline Age $>65 y r$ & $53(61)$ & $282(44.7)$ & ns \\
\hline Dicumarine & $9(10.3)$ & $33(5.2)$ & ns \\
\hline Corticosteroids & $3(3.4)$ & $6(1.0)$ & ns \\
\hline \multicolumn{4}{|l|}{ Cardiovascular risk factors } \\
\hline Nicotine $(n=710)$ & $26(29.9)$ & $218(34.5)$ & ns \\
\hline Hypercholesterinemia $(n=712)$ & $85(97.7)$ & $601(95.2)$ & ns \\
\hline Hypertension $(n=712)$ & $69(79.3)$ & $392(62.1)$ & 0.002 \\
\hline Diabetes $(n=707)$ & $11(12.6)$ & $100(15.8)$ & ns \\
\hline Family history $(n=709)$ & $18(20.7)$ & $141(22.3)$ & ns \\
\hline
\end{tabular}

E endoscopic diagnosis; $n s$ not significant; * ENT Ear Nose Throat. 
uncomplicated GI-lesions without bleeding (erosions and ulcers), typical GI symptoms as dyspepsia and black stool in patients without endoscopy.

\section{Risk profile}

Patients with an UGI-AE were investigated further for the risk factors age $>65 \mathrm{y}$, concomitant use of steroids, dicumarine and NSAID, H. pylori infection and previous peptic disease.

\section{Statistical analysis}

Fisher's exact test was used to test for significant differences in presence of UGI-AEs by the various risk factors. Additionally, multiple logistic regression (Hosmer and Lemeshow [2000]) [18] was used to examine the effect of all risk factors simultaneously. $P$-values have not been adjusted for multiple testing. All analyses were performed in the R programming language [19].

\section{Results}

\section{Exclusion criteria}

Among the 1500 patient files, which were selected from the cardiologic database, 718 patients with PCI and combination antiplatelet therapy qualified for further analysis. 657 patients were excluded for various reasons, as described in detail in Fig. 1.

Additionally, 125 patients were on monotherapy (=aspirin or clopidogrel for 12 months). $18.9 \%$ of them had UGI-AE vs $12 \%$ with UGI-AE on combination antiplatelet therapy. Monotherapy did not show a different spectrum of UGI-AE compared to patients with combination antiplatelet therapy. They were not considered for further analyses. Baseline characteristics are given in Tab. 1.

\section{Primary and secondary endpoints}

Primary endpoints (SAE) were observed in 5 patients $(0.7 \%)$. All SAEs resulted in prolongation of hospitalisation. Details of patients ( 3 male and 2 female) with SAE are presented in Tab. 2 .
Secondary endpoints were found in $81(11.3 \%)$ patients. 57 were male and 24 female: Erosions $(n=4$, $0.6 \%)$, black stool $(n=14,2.0 \%)$, dyspepsia $(n=63$, $8.8 \%)$.

\section{PPI and UGI-AE}

UGI-AE occurred in $86(12.0 \%)$ patients. 16 of these were on prophylactic PPI and 70 had no acid suppression. There was no difference in the frequency and severity of UGI-AE in the groups with and without PPI ( $p=0.57)$ and there was no difference in type of PPI, either.

Considering the entire study cohort $(n=718), 87$ (12.1\%) patients were treated with prophylactic PPI. In these 87 patients, UGI-AE occurred in $16(18.4 \%)$. In the group without prophylactic PPI $(n=631,87.9 \%)$, UGI-AE was observed in 70 (11.1\%) patients (Tab. 3). Considering only the data in the group without PPI prophylaxis the number needed to treat (NNT) with a prophylactic PPI to prevent one UGI-AE was 14.

\section{Risk factors in patients with prophylactic PPI medication}

Despite co-treatment with prophylactic PPI, UGI-AE occurred in 16 patients. Table 4 shows their risk factor profile and PPI dose.

There was no difference in the dose of PPIs between patients with and without AE. Age $>65 \mathrm{y}$ was the most frequent risk factor and was found in $53(69 \%)$, second in line was dicumarine with a total of $7(8 \%)$.

\section{Predictive factors for UGI-AE}

For the whole study cohort $(n=718)$, the risk factors age $>65 \mathrm{y}(326 / 718,45.4 \%)$, steroids $(9 / 718,1.2 \%)$, dicumarine $(42 / 718,5.8 \%)$ and prescription of prophylactic PPI (631/718, 87.9\%) were analysed. The results of the logistic regression analysis are given in Tab. 5 . This multivariate analysis demonstrated that patients with prescription of steroids had a significantly higher incidence of UGI-AE. Steroids had a significant impact on the rate of UGI-AE after adjustment for age, dicumarine

\section{Tab. 2: Risk profile of patients with UGI-SAE $(n=5)$}

\begin{tabular}{lllllll}
\hline Diagnosis & $\begin{array}{l}\text { Prophylactic } \\
\text { PPI }\end{array}$ & $\begin{array}{l}\text { Age }>65 \\
\text { years }\end{array}$ & Dicumarine & NSAID & Corticosteroids & $\begin{array}{l}\text { Ulcer } \\
\text { history }\end{array}$ \\
\hline Peptic ulcer $(n=3)$ & 0 & 2 & 0 & 1 & 0 & 0 \\
\hline No source** $^{*}(n=2)$ & $1^{* * *}$ & 2 & 1 & 0 & 0 & 0 \\
\hline
\end{tabular}

${ }^{*}$ Two patients had a gastric ulcer, one patient had a duodenal ulcer; ${ }^{* *}$ One patient had black stool, one patient had hematemesis but no endoscopic finding; ${ }^{* * *}$ Double standard dose: Lansoprazole $30 \mathrm{mg} / 40 \mathrm{mg}$ of every other PPI. 
Tab. 3: Prophylactic PPI therapy in patients with versus without UGI-AE in the whole study population $n=718$ )

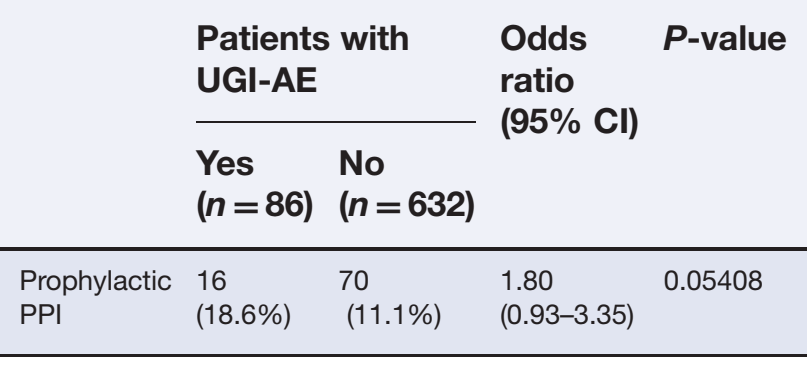

and prophylactic PPI, with an OR of 5.45 (CI 1.30-21.35, $P=0.0142$ ). Age $>65 \mathrm{y}$, dicumarine co-treatment and lack of prophylactic PPI were not independent risk factors for UGI-AEs.

In the subgroup analysis of patients with UGI-AE and without prophylactic PPI $(n=70)$, the presence of ulcer history, NSAID co-treatment and H.pylori-infection were not independent risk factors for UGI-AEs.

\section{Discussion}

This cohort comprised 718 patients with PCI requiring combination antiplatelet therapy with aspirin and clopidogrel for at least 12 months after the intervention according to the guidelines of the European Society of Cardiology [1]. This was an observational study with the aim to analyse the practice of an individualised prescription of PPIs in patients on combination antiplatelet therapy and to investigate its role in prevention of UGI-AEs.

The incidence of UGI-AE in this study was $12.0 \%$, including $0.8 \%$ endoscopically diagnosed lesions (=UGI bleeding, ulcer, erosion) and $0.7 \%$ UGISAE. Previous trials yielded comparable incidences of UGI-AE: The CURE and the MATCH study had an incidence of major GI-bleeding episodes (i.e. SAE) of $0.84 \%$ and $0.421 \%$, respectively $[3,20]$. In a Chinese multicentre retrospective study on combination antiplatelet therapy, patients developed a comparable rate of endoscopically proven ulcer and erosion as in our study, namely $0.8 \%$ [21].

Efficacy of PPIs in prevention of UGI-AE has been confirmed in different studies previously $[11,12$, 22-27]. However, a beneficial effect could not be shown in this study (OR 1.80, 95\% CI 0.926-3.352, $P=0.05408$ ) when comparing patients with PPI and those without. All over, only 87 of 718 (12.1\%) patients had prophylactic PPI therapy after PCI. However, this low prescription rate is in line with three other studies performed in a similar setting showing rates between 5.7 and $27.6 \%$ [11, $12,28]$. In contrast to our observation these studies showed a significant decrease in UGI-AE in patients with prophylactic PPI. However, these studies differ from our cohort as regards indication and study population: Patients may have benefited more from a PPI prophylaxis as they had an increased GI risk profile compared to our cohort since they were significantly older than our patients 72.1 vs $64 \mathrm{yrs}$ [11] and were more often on enoxaparin during hospitalisation [11, 12]. In addition a large Japanese study [28] was performed in patients with aspirin and thienopyridine derivates (ticlopidine) instead of clopidogrel and can therefore not be compared adequately.

The tendency in our cohort study for having a UGI-AE while being on PPI therapy may be explained by a selection bias: Patients had PPIs for different reasons, such as ulcer history, concomitant NSAID-use and age $>65 \mathrm{y}$, and were therefore already at increased risk for bleeding despite acid suppression. This is in contrary to randomised trials with matching of patients in a PPI group and a non-PPI group according to their UGI-bleeding risk [11, 12, 28].

According to previous studies, patients with the following conditions are at high risk and will possibly benefit from prophylactic PPI treatment after PCI: patients with a history of ulcer disease, concomitant NSAID-use, concomitant Dicumarine-use, H. pylori infection, and age $>65$ years [6-9]. In this study, concomitant use of corticosteroids was proven to be an independent risk factor for UGI-AE after adjustment for

Tab. 4: Risk factors and PPI dose in patients with UGI-AE and prophylactic PPI $(n=16)$

\begin{tabular}{llllllll} 
& $\begin{array}{l}\text { Age } \\
>65\end{array}$ & Dicumarine & Steroids & Ulcer history & NSAID & $\begin{array}{l}\text { PPI } \\
\text { standard } \\
\text { dose* }\end{array}$ & $\begin{array}{l}\text { PPI double } \\
\text { standard } \\
\text { dose** }\end{array}$ \\
\hline Erosion $(n=2)$ & 1 & 0 & 0 & 1 & 0 & 1 & 1 \\
\hline Overt bleeding*** $(n=3)$ & 3 & 2 & 0 & 1 & 0 & 0 & 3 \\
\hline Dyspepsia $(n=11)$ & 6 & 2 & 1 & 4 & 3 & 5 & 6 \\
\hline
\end{tabular}

"Lansoprazole $15 \mathrm{mg} / 10-20 \mathrm{mg}$ of every other PPI; ** Lansoprazole $30 \mathrm{mg} / 40 \mathrm{mg}$ of every other PPI; ***Black stool, hematemesis. 
Tab. 5: Adjusted odds ratio for UGI-AE in the study population $(n=718)$

\begin{tabular}{llll}
$\begin{array}{l}\text { Number of } \\
\text { patients with } \\
\text { UGI-AE (\%) }\end{array}$ & $\begin{array}{l}\text { Odds } \\
\text { ratio }\end{array}$ & $\begin{array}{l}\boldsymbol{P} \text { - } \\
\text { value }\end{array}$ \\
\cline { 1 - 2 } $\begin{array}{l}\text { Yes } \\
(\boldsymbol{n}=\mathbf{8 6})\end{array}$ & $\begin{array}{l}\text { No } \\
(\boldsymbol{n}=632)\end{array}$ & \\
\hline $40(46.5)$ & $46(7.3)$ & $0.98(0.62-1.55)$ & 0.9377 \\
\hline $4(4.6)$ & $82(13.0)$ & $5.45(1.30-21.35)$ & 0.0142 \\
\hline $7(8.1)$ & $79(12.5)$ & $1.39(0.54-3.12)$ & 0.4584 \\
\hline $16(18.6)$ & $70(11.1)$ & $1.68(0.88-3.04)$ & 0.0980 \\
\hline
\end{tabular}

*Overt bleeding $(n=1)$, dyspepsia $(n=4)$.

age, dicumarine and absence of PPI treatment (OR5.45, 95\% CI 1.30-21.35, $P=0.0142$ ) and increased the risk for UGI-AE 3.8-fold. This is in line with the current literature, showing a 2-fold increased risk for UGI-AE in patients on long-term NSAID therapy and corticosteroids $[5,24]$.

\section{Conclusion}

Patients judged by their physician not to need a PPI showed a trend for fewer UGI-AE than patients on PPI therapy. Thus, the need for a PPI prophylaxis as elucidated individually by GPs based on a risk assessment for UGI-bleeding seems to be an effective measure to minimise UGI-AE after PCI. Whether patients with UGI-risk factors were treated inadequately as concerns the dose of PPI and adherence to PPI medication cannot be precisely answered in this study. An individualised prescription practice of PPIs seems to be still adequate and may prevent an overuse of PPI-therapy especially in the light of interactions with clopidogrel.

Further prospective studies on the value of a prophylactic PPI medication in patients at low risk for UGI-AE should address this question.

\section{Conflict of interest}

Rahel Häuptle, Daniel Weilenmann, Tino Schneider, Sarah R. Haile, Peter Ammann, Christina Knellwolf, and Jan Borovicka declare that there is no conflict of interest.

\section{Financial support}

\author{
Kantonsspital St. Gallen
}

\section{References}

[1] Silber S, Albertsson P, Aviles FF, et al. Guidelines for percutaneous coronary interventions. The Task Force for Percutaneous Coronary Interventions of the European Society of Cardiology. Eur Heart J, 26: 804-847, 2005.

[2] Mehta SR, Yusuf S, Peters RJ, et al. Effects of pretreatment with clopidogrel and aspirin followed by long-term therapy in patients undergoing percutaneous coronary intervention: the PCI-CURE study. Lancet, 358(9281): 527-533, 2001.

[3] Diener HC, Bogousslavsky J, Brass LM, et al. Aspirin and clopidogrel compared with clopidogrel alone after recent ischaemic stroke or transient ischaemic attack in high-risk patients (MATCH): randomised, double-blind, placebo-controlled trial. Lancet, 364(9431): 331-337, 2004.

[4] McQuaid KR, Laine L. Systematic review and meta-analysis of adverse events of low-dose aspirin and clopidogrel in randomized controlled trials. Am J Med, 119: 624-638, 2006.

[5] Laine L. GI risk and risk factors of NSAIDs. J Cardiovasc Pharmacol, 47(Suppl 1): S60-S66, 2006.

[6] Byrne MF, Murray FE. Formulary management of proton pump inhibitors. Pharmacoeconomics, 16: 225-246, 1999.

[7] Herings RM, Goettsch WG. Inadequate prevention of NSAID-induced gastrointestinal events. Ann Pharmacother, 38: 760-763, 2004.

[8] Lanas A, Scheiman J. Low-dose aspirin and upper gastrointestinal damage: epidemiology, prevention and treatment. Curr Med Res Opin, 23: 163-173, 2007.

[9] Bhatt DL, Scheiman J, Abraham NS, et al. ACCF/ACG/AHA 2008 expert consensus document on reducing the gastrointestinal risks of antiplatelet therapy and NSAID use: a report of the American College of Cardiology Foundation Task Force on Clinical Expert Consensus Documents. J Am Coll Cardiol, 52: 1502-1517, 2008.

[10] Ibanez L, Vidal X, Vendrell L, et al. Upper gastrointestinal bleeding associated with antiplatelet drugs. Aliment Pharmacol Ther, 23: 235-242, 2006.

[11] Ng FH, Lam KF, Wong SY, et al. Upper gastrointestinal bleeding in patients with aspirin and clopidogrel co-therapy. Digestion, 77: 173-177, 2008.

[12] Ng FH, Wong SY, Lam KF, et al. Gastrointestinal bleeding in patients receiving a combination of aspirin, clopidogrel, and enoxaparin in acute coronary syndrome. Am J Gastroenterol, 103: 865-871, 2008.

[13] Hsiao FY, Tsai YW, Huang WF, et al. A comparison of aspirin and clopidogrel with or without proton pump inhibitors for the secondary prevention of cardiovascular events in patients at high risk for gastrointestinal bleeding. Clin Ther, 31: 2038-2047, 2009.

[14] Ray WA, Murray KT, Griffin MR, et al. Outcomes with concurrent use of clopidogrel and proton-pump inhibitors: a cohort study. Ann Intern Med, 152: 337-345, 2010.

[15] O'Donoghue ML, Braunwald E, Antman EM, et al. Pharmacodynamic effect and clinical efficacy of clopidogrel and prasugrel with or without a proton-pump inhibitor: an analysis of two randomised trials. Lancet, 374(9694): 989-997, 2009.

[16] Hsu PI, Lai KH, Liu CP. Esomeprazole with clopidogrel reduces peptic ulcer recurrence, compared with clopidogrel alone, in patients with atherosclerosis. Gastroenterology, 140: 791-798, 2011.

[17] Bhatt DL, Cryer BL, Contant CF, et al. Clopidogrel with or without omeprazole in coronary artery disease. N Engl J Med, 363: 1909-1917, 2010. 